\title{
Characterization of Anxiety Towards Mathematics in Middle School Students: Empirical Evidence
}

\author{
Arturo García-Santillán ${ }^{1}$, Lizzeth Navarro-Ibarra ${ }^{2}$, Esmeralda Tejada-Peña ${ }^{3}$ \\ ${ }^{1}$ UCC Business School, Cristóbal Colón University \& Misantla Institute of Technology (MIT), Carretera \\ Veracruz Medellin, Puente Moreno S/N Boca del Río, Ver., México \\ ${ }^{2}$ Instituto Tecnológico de Sonora, Av. Antonio Caso S/N Cd. Obregón, Son., México \\ ${ }^{3}$ Tecnológico nacional de México campus Tuxtepec. Privada de reforma número 5 colonia el castillo, \\ San Juan Bautista Tuxtepec, Oaxaca, México
}

\begin{abstract}
The study focuses on determining the level of anxiety towards mathematics in middle school students. A total of 202 students were surveyed. The main finding obtained is the factorial structure, which is made up of three factors that explain $79 \%$ of the total variance of the phenomenon under study (Mathcourse .893; Mathtest .890 and Mathtask .884) which is represented by an eigenvalue $(2,371)$. Finally, it was found that there is a difference in relation to gender in two factors Mathtest $(F=14.282)$ and Mathtasks $(F=4.004)$.
\end{abstract}

Keywords - Mathematics anxiety, Middle school students, Rural schools, Factor analysis.

\section{Introduction}

The teaching of mathematics has been fundamental in formal education study programs, from elementary level to superior learning.

DOI: 10.18421/TEM111-32

https://doi.org/10.18421/TEM111-32

Corresponding author: Lizzeth Navarro-lbarra, Instituto Tecnológico de Sonora, Av. Antonio Caso S/N Cd. Obregón, Son., México.

Email: lizzeth.navarro@gmail.com

Received: 09 December 2021.

Revised: 27 January 2022.

Accepted: 03 February 2022.

Published: 28 February 2022.

(c)) BY-Nc-ND@ 2022 Arturo García-Santillán, Lizzeth Navarro-Ibarra \& Esmeralda Tejada-Peña; published by UIKTEN. This work is licensed under the Creative Commons Attribution-NonCommercial-NoDerivs 4.0 License.

The article is published with Open Access at https://www.temjournal.com/
This science stands out for its abstraction and generality of concepts, as well as for the cognitive power generated from learning it, favoring the intellectual development through the achievement of capabilities, skills and abilities. It has, however, become cognitive and emotional barrier for many students [1].

The difference in student's academic achievement in mathematics has spurred the search for the root causes of this. There are studies oriented to cognitive [2], attitudinal [3], emotional and affective factors [4].

To determine the achievement in mathematics in Mexico, as part of the Program for International Student Assessment (PISA), the standardized test for mathematics has been applied every three years. This assessment is applied to 15-year-old students and its purpose is to identify the learning and abilities achieved by them.

In the assessment applied from 2003 to 2015, Mexico has had an improvement of five points in average between each of the tests. Nonetheless, the 2015 results (408 points) place Mexican students below the average (490 points) of the countries that are part of the Organization for Economic Cooperation and Development (OECD). Furthermore, the score obtained in 2015 is below that of 2009, 419 points [5].

Moreover, the test divides the competencies shown in the items are divided in seven proficiency levels. The lowest classification is denominated "below level 1" located at below 368 points. The highest is level 6 (more than 668 points). The student's score locates them in level 1 (from 358 to 420 points) which indicates the capacity to identify information and develop routine procedures in accordance to explicit instructions. Nevertheless, incapable of employing algorithms and formulas and much less interpret, reflect upon and reason. 
In addition to PISA, the Mexican government designed $a$ test to measure proficiency in mathematics, language and communication through the National Plan for Learning Assessment (Plan Nacional para la Evaluación de los Aprendizajes, PLANEA). This assessment has been applied on a yearly basis since 2015 . The instruments classify the achievement levels as insufficient, elementary, satisfactory and overachieving or advanced. $66 \%$ of students were located at the insufficient knowledge level in the 2017 assessment, reflecting an absence of the basic core knowledge which will hinder academic advancement. $23 \%$ was located in the elementary category and only $11 \%$ complies with satisfactory or advanced achievement [6].

Dominance in mathematics is fundamental for academic and daily life success. However, a lot of people experiment fear and apprehension when having to deal with numbers, this is what is called anxiety towards mathematics [7]. Various studies have inquired about the dimensions that make up this construct [8]. Furthermore, others researches look to determine differences in anxiety by gender [9], age and school year [10]. Even so, the anxiety phenomenon requires a more in-depth study that manages to identify the originating factors in different contexts in order to be able to establish actions that diminish it.

With this approach the general objective of this study is to identify the group of factors that allow to explain the phenomenon of anxiety towards mathematics. Conforming to the aforementioned, the following hypothesis are established:

$\mathrm{H} 1_{\mathrm{O}}$ : There is no group of factors that determine anxiety towards mathematics.

$\mathrm{H}_{1}$ : There is a group of factors that determine anxiety towards mathematics.

$\mathrm{H} 2_{\mathrm{O}}$ : The level of anxiety towards mathematics doesn't differ by gender.

$\mathrm{H} 2_{\mathrm{i}}$ : The level of anxiety towards mathematics differs by gender.

\section{Literature Review}

The research took place in a Telebachillerato that is part of the Mexican school system. This is the reason for the description of the characteristics and context this learning option is found in.

The Telebachillerato Comunitario (TBC) is a public learning option for high school level in Mexico. They are located in rural communities with less than 2500 inhabitants who do not have access to high school in a 5 kilometre radius.

The TBC study programs comply with the precepts of the integral reform of high school education (Reforma Integral de la Educación Media Superior, RIEMS) and has a competencies focus. The learning is achieved through formative and community projects that integrate knowledge from the different learning areas (Mathematics and Experimental Sciences, Social Sciences and Humanities and Communication).

The teaching modality is on-site, which is to say, they have to be present in school for a period of 6 hours a day and their academic preparation is concluded in three years. The subjects are given through a combination of printed and audio-visual material, always with the support of a teacher. The physical infrastructure TBC uses comes from middle schools or televised middle schools (telesecundarias) which are in turn used in available open schedules.

TBC as well as the number of students enrolled has been growing during the last few years. During the school year of 2013-2014 there were 253 schools with 4,500 students, while for the 2017-2018 school year there were 3,311 schools with 131,451 students enrolled. On the other hand, the construct of anxiety towards mathematics has been studied with different approaches, scopes and purposes. This started in the 1950's through mathematics teachers' observations. They detected the presence of a syndrome by the emotional reactions to mathematics. However, there are difficulties in defining and measuring anxiety towards mathematics, proposals have been made, such as [11].

According to [12] the anxiety measurement has developed over three stages. In the first stage, research was supported by the opinions of the researchers without employing standardized measurements. The term math phobia was initially used by [13] referring to the impact in emotional responses of students when facing mathematics homework and challenges. In turn, [14] defined the mathematics anxiety construct as anxiety towards numbers. On the other hand, [15] define mathematics anxiety as feelings of tension and anxiety that disrupt number manipulation and solving math problems.

In a second stage studies were focused in the assessment of attitudes towards math through confidence, enjoyment and erroneous concepts. The scales were unidimensional, with variables such as feelings towards mathematics [16].

During the third stage standardized and more complete scales were developed, such as the Mathematics Anxiety Rating Scale [15], the Fennema-Sherman Math Attitude Scales [17] and Anxiety Towards Mathematics Scale [18].

The instrument developed by Richardson and Suinn named Mathematics Anxiety Rating Scale (MARS) is formed by 98 items about routine and formal math experiences. The answer options are Likert type answers from 1 to 5. During a test-retest period of seven weeks a reliability of .85 was obtained with an internal reliability coefficient of .97. 
Other studies have developed shorter versions of the scale (MARS). A scale named Mathematics Anxiety Rating Scale-Revised (MARS-R) consisting of 24 items was presented by [19] where two factors were identified. One of the subscales was labelled as "Learning Math Anxiety" (LMA) and the other as "Mathematic Evaluation Anxiety" (MEA). The alpha reliability coefficient was .98 , improving the .97 of the original scale.

Also, [20] elaborate another version of the instrument with 30 items. The Cronbach's alpha obtained for that scale is .96 showing a high internal reliability. The test-retest reliability was $.90(\mathrm{p}<$ .001). This data confirms that the instrument has a validity comparable to that of the original.

[21] revised the MARS-R and shortened it from 24 to 12 items. In the LMA dimension an alpha reliability coefficient of .87 was obtained, while in the MEA .85 was achieved. Both factors highly correlated $(\mathrm{r}=0.72)$.

The Revised Mathematics Anxiety Rating Scale (RMARS) of [22], is also an abbreviated version or the MARS scale and it composed of 25 items. The instrument is comprised of three subscales. One of the components is the math evaluations that measure the reactions of students confronted with situations where they are evaluated. Another factor are the courses and is used to identify behavior when inside a math class. The third subscale is about tasks, specifically about basic operations such as multiplication and division. The RMARS scale correlates by .93 with the MARS scale and exhibited a reliability of .86 in a two-week test-retest. Furthermore, the alpha coefficient for the factors was of $.96, .86$ and .84 .

Later on, [23], also developed an instrument to measure math attitude of students in compulsory secondary education in Spain. The questionnaire is formed by 24 items with a.95 Conbach's alpha. The scale is made up of five math anxiety factors: evaluation, temporality, problem comprehension, numbers and operations and real-world mathematics. Within the Mexican context the scale validity developed by [23] is ratified by [24] for middle school level and [25] for telesecundaria (It is a system of distance education programs for secondary students).

Additionally, other studies have found differences by gender in attitudes towards math. [26] determined a statistically significant recurrence by gender; however, the size of the effect is lacking for which there could be another strange variable influencing the results.
[27] also obtained significant variations between men and women concerning math anxiety. The least anxiety towards math was identified in males; nonetheless, the wilfulness to express said anxiety was not evaluated. Likewise, [28] identified a higher level of anxiety in female students.

In one meta-analysis by [29] using the results of 151 studies about the math anxiety construct, women were found to exhibit higher levels of anxiety than men. In the same way, differences by gender were described by [30], while women manifested significantly higher anxiety when facing math exams, men expressed a superior anxiety when faced with math activities or tasks. In contrast, studies like [31] have not found an influence in the gender variable about math anxiety in students.

The variables involved in the problem are described and presented as an initial approach, thus integrating the following conceptual theoretical model (Figure 1).

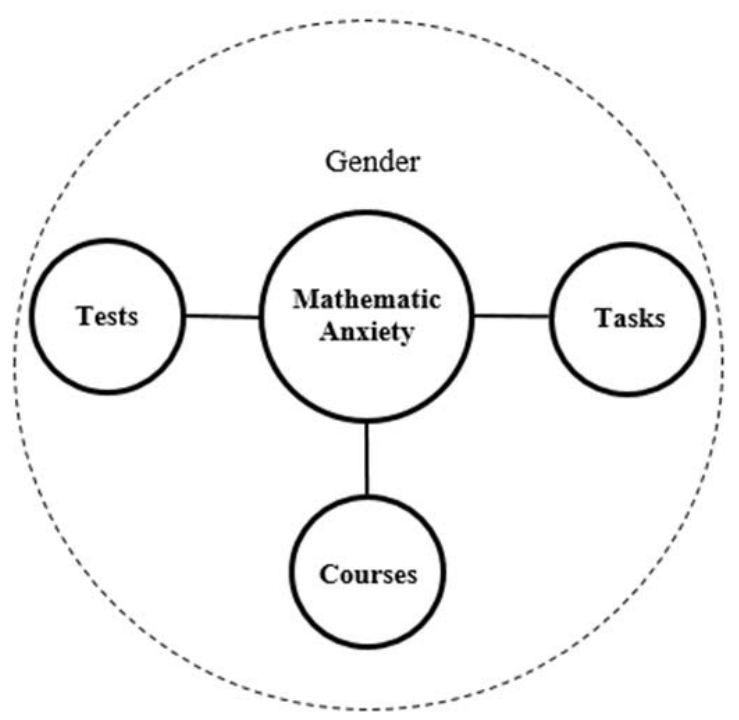

Figure 1. Conceptual theoretical model of the RMARS scale [22]

Source: by author

\section{Methodological Design}

In order to conduct the empirical study, this research is of a non-experimental cross-section design, which is approached from the hypotheticaldeductive paradigm, of explanatory correlational type. It is non-experimental due to the fact that there is no independent variables manipulation that could condition or modify the effects (dependent variables), and cross-section every instance that the field application is carried out in a single period of time of the research. Moreover, in order to measure the way in which two or more variables interact, the factors that explain math anxiety are evaluated in Telebachillerato students located in the suburban zones of the state of Veracruz, therefore making the study an explanatory correlational type. 


\subsection{Methodological Design}

The target population of the study was constituted by students enrolled the regular semester AugustDecember 2017, who were studying their $1^{\circ}, 3^{\circ}$ and $5^{\circ}$ Telebachillerato semester. The institutions are located in the municipalities of Tejería and Medellín in the state of Veracruz, México.

The ages of the students fluctuate between 14 and 19 years old, where at least $80 \%$ of them come from dysfunctional families, which is to say, they either live with their mother or father, or some other relative. The context of the localities is suburban where households have basic services available.

\subsection{Sample}

The sample for this study is non-probabilistic by convenience. The inclusion criterion enrolled students in a regular semester that agreed to answer the questionnaire voluntarily, being previously approved by the institution's education authorities. The survey was answered in paper by the students, anonymously, during class hours and in the presence of the researcher.

The sample is integrated by 79 students from the first semester, 65 from the third semester and 56 from fifth, giving a total of 200 participants.

\subsection{Procedure}

The relationship between the variables will be obtained through multivariate factor analysis with component extraction. Before proceeding with the aforementioned technique, a validation of the scale is conducted using Cronbach's Alpha, the Bartlett sphericity test with Kaizer KMO to identify the factor analysis pertinence, $\mathrm{X}^{2}$ with degrees of liberty, significance $(\alpha=.01)$, measure of sampling adequacy (MSA) and a factor load of .70. The factor analysis with the aforementioned criterion has been implemented in recent studies [32].

At the same time, the null hypothesis $(\mathrm{Ho}=0)$ shows there is no correlation and the alternative hypothesis $(\mathrm{Hi} \neq 0)$ shows there is a correlation. Equally, the determinant to reject the null hypothesis Ho is if the calculated $X^{2}$ is bigger than $X^{2}$ from tables.

The difference between groups was evaluated through the ANOVA analysis, the idea being to know if the population means are equal or differ in at least one case. With this ANOVA process the null hypothesis in which the $\mathrm{K}$ population means $(\mathrm{K}>2)$ are equal is contrasted against the alternate hypothesis which suggests that at least one of the populations is different from the others, in relation to its expected value [33].

\section{Results}

In the $\mathrm{H}_{1}$ hypothesis the existence of a group of factors that explain math anxiety is established, in order to assess this statement, the calculation of Cronbach's alpha was applied before determining the pertinence to undergo the factor analysis. Table 1 presents the Cronbach's alpha values of the RMARS scale.

Table 1. Reliability analysis of RMARS scale

\begin{tabular}{|clcc||}
\hline \hline Factors or dimensions & $\alpha$ & Valid & Excluded \\
25 factors & .94 & 200 & 0 \\
3 dimensions & .74 & & \\
\hline
\end{tabular}

As seen in Table 1, the values of Cronbach's alpha for all items is .94 and .74 for three-dimensional grouping, which is greater than .70 which according [34] is adequate. Therefore, the scale complies with the qualities of internal consistency and reliability established for the instrument's validity.

It was verified afterward if the factor analysis was the appropriate method according to the research data. For it, Bartlett's sphericity test was applied and the measure of sampling adequacy (MSA).

Bartlett's sphericity test with Kaizer-Meyer-Olgkin (KMO) evaluates if the correlations matrix is an identity matrix where the values fluctuate between 0 and 1 . In the case of a KMO lower than .5 that would demonstrate that the correlations between variables could not be explained by other variables, and for that reason the method of factor analysis would not be appropriate for this data. The KMO and Bartlett's sphericity test are shown in Table 2 .

Table 2. KMO and Bartlett's sphericity test

\begin{tabular}{||cccc|}
\hline \multirow{2}{*}{ KMO } & \multicolumn{3}{c|}{ Bartlett's sphericity test } \\
& Aproximate Chi-square & $\mathrm{df}$ & $\mathrm{p}$ \\
.739 & 286.057 & 3 & .000 \\
\hline
\end{tabular}

The calculated value $\left(X^{2}=286.057 ; \mathrm{df}=3 ; \mathrm{p}<\right.$ $.000)$ is higher than the theoretical value from tables $\left(X^{2}=16.266 ; \mathrm{df}=3 ; \mathrm{p}<.001\right)$ which hives evidence to reject Ho according to the criterion previously established for the acceptance or rejection of the null hypothesis. Thus, the null hypothesis can be rejected, which states the non-existence of a correlation among the variables being studied, because contrary to this the existence of acceptable correlations was proven for the group of latent variables belonging to the analyzed phenomenon. Moreover, the value obtained for $\mathrm{KMO}=.739$ is higher than .5 which in theoretical terms is an acceptable value supporting the development of the statistical method. Because of this is that the factor analysis for this data is adequate [33]. In support of these arguments, the correlations matrix is shown in Table 3, where we can observe acceptable correlations, all of them higher than .5 . 
Table 3. Correlations matrix

\begin{tabular}{|lccc||}
\hline \multicolumn{1}{|c}{ Dimension } & MATH & MATH & MATH \\
MATHTEST & TEST & TASKS & COURSES \\
MATHTASKS & 1.000 & & \\
MATHCOURSES & .676 & 1.000 & \\
\hline
\end{tabular}

Table 4 presents the measure of sampling adequacy for each dimension, whose values have to be near to lin order to determine if the factor analysis method is adequate for the explanation of the gathered data. In this case the MSA values are located between .730 and .751, resulting in significant, thus confirming that the factor analysis method is optimal for the phenomenon under study.

Table 4. MSA values by dimension

\begin{tabular}{||cc|}
\hline \multicolumn{1}{|c|}{ Dimension } & MSA \\
MATHTEST & .737 \\
MATHTASKS & .751 \\
MATHCOURSES & .730 \\
\hline
\end{tabular}

Once having confirmed that the factor analysis method is adequate for this research, the component of factors determination was started. The extraction and rotation of the components was undertaken under the premise of an eigenvalue higher than one. Table 5 describes the components, communalities, eigenvalue and the total explained variance.

Table 5. Main components, communality, eigenvalue and total variance

\begin{tabular}{|lcc||}
\hline \multicolumn{1}{|c}{ Dimension } & Component 1 & Communality \\
MATHTEST & .890 & .781 \\
MATHTASKS & .884 & .798 \\
MATHCOURSES & .893 & .792 \\
Eigenvalue & & 2.371 \\
Total explained & \multicolumn{3}{c}{$79 \%$} \\
variance & & \\
\hline
\end{tabular}

A value higher than one (2.371) signals the existence of a factor with a total explained variance of $79 \%$ of the total data variation. In the same way, the loads for all three factors are presented in Table 5 which were obtained in the extraction of the main components. In this analysis the three factors that make up component 1 have a factor load higher than .5 .

The dimension called Mathcourses shows the highest factor load (.893) and it refers to anxiety for math courses. The Mathtest dimension, which indicates anxiety for math tests has a slightly lower value (.890) and, lastly Mathtasks dimension is about anxiety for math activities (.884).
Concerning the proportion of variance explained by the communality, the result was that Mathtasks was the highest with .798, Mathcourses following next with -792 and the lowest value was Mathtest with .781 .

Besides that, to contrast $\mathrm{H}_{2}$ hypothesis, which states that there are significant differences between the factors that originate math anxiety in TBC in respect to gender, the data is processed with the factor "gender", again utilizing the three grouped dimensions. Previous to the ANOVA test, it is proven that the samples belong to a population with the same variance.

The verification of homogeneity of variances is carried out with Levene's test for the homoscedasticity hypothesis contrast. Table 6 shows the Levene test for every dimension, where all values are sufficiently small and with a significance higher than .5 for all variables. The former allows accepting the variances equality hypothesis, in other words, the samples come from a population with the same variance.

Table 6. Homogeneity test of population variances by gender grouped by dimension

\begin{tabular}{lcccc}
\hline \multicolumn{1}{c}{ Dimension } & $\begin{array}{c}\text { Levene's } \\
\text { test }\end{array}$ & df1 & df2 & $\mathrm{p}$ \\
\hline MATHTEST & .852 & 1 & 198 & .357 \\
MATHTASKS & 1.411 & 1 & 198 & .236 \\
MATHCOURSES & .298 & 1 & 198 & .586 \\
\hline
\end{tabular}

Once it has been determined that the samples belong to a population with the same variance, we proceed with the ANOVA test (see Table 7), where the F-test statistic of Mathtest variable is $(\mathrm{F}(1,198)$ $=14.282 ; \mathrm{p}<.000)$; and of the Mathtasks variable is $(\mathrm{F}(1,198)=4.004 ; \mathrm{p}<.047)$; since the $\mathrm{F}$ statistical value is higher than the critical value $(\mathrm{F}(1,198)=$ 3.888 ) the mean equality hypothesis is rejected. Because of the aforementioned, it can be stated that the level of test and tasks anxiety for TBC students differs in respect to gender. In addition, the level of significance is lower than .5 , therefore rejecting the means equality hypothesis, which is to say, there are significant differences between the groups.

In respect to the variable Mathcourses, Table 7 shows $(\mathrm{F}(1,198)=.881 ; \mathrm{p}<.349)$, this is lower than the critical value $(F(1,198)=3.888)$ for which the means equality hypothesis can't be rejected. At the same time, the level of significance is higher than .05 so the means equality hypothesis can't be rejected, signifying that there are no significant differences among the groups. For which, the math course anxiety level of TBC students does not differ in respect to gender. 
Table 7. ANOVA by gender and grouped by dimension

\begin{tabular}{||ccccccc||}
\hline \multirow{2}{*}{ Dimension } & $\begin{array}{c}\text { Sum of } \\
\text { squares }\end{array}$ & df & $\begin{array}{c}\text { Squared } \\
\text { mean }\end{array}$ & $\mathrm{F}$ & $\mathrm{p}$ \\
MATH & Inter & 2127.0 & 1 & 2127.0 & 14.2 & .000 \\
TEST & Intra & 29487.9 & 198 & 148.9 & & \\
& Total & 31614.9 & 199 & & & \\
MATH & Inter & 86.0 & 1 & 86.0 & 4.0 & .047 \\
TASKS & Intra & 4254.9 & 198 & 21.4 & & \\
& Total & 4340.9 & 199 & & & \\
MATH & Inter & 23.6 & 1 & 23.6 & .88 & .349 \\
COURSES & Intra & 5306.1 & 198 & 26.8 & & \\
& Total & 5329.7 & 199 & & & \\
\hline
\end{tabular}

\section{Conclusions}

The math anxiety level manifested in students influences their academic performance, which supports the need to create actions that lead to the decline of anxiety and by doing so favor the attitude toward learning mathematics. The data collected from TBC students through the RMARS scale [22] were examined the multivariant factor analysis with component extraction method.

Through this test, the evidence was obtained for the formation of three factors to explain math anxiety. The phenomenon under study, being math anxiety, formed a factor with $79 \%$ of total variance explained from the variable math courses, tests and tasks. These findings coincide with those found by [8], [22] as shown in Figure 2.

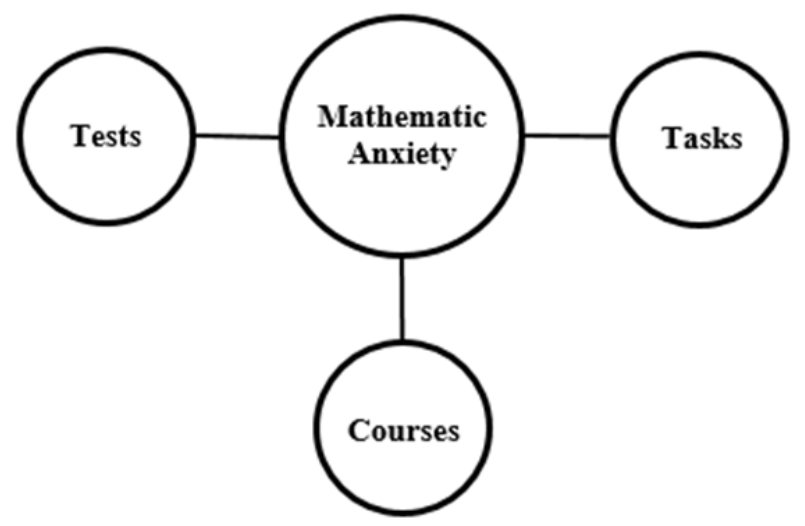

Figure 2. Three component model of the RMARS scale Source: by author

In terms of the correlation between variables, the highest was among Mathcourses and Mathtest with .697. The factor load of the created component allows to determine that the variable math courses (.893) it the originator of the highest anxiety, followed by tests (.890) and, lastly math tasks (.884).

Conversely, with the ANOVA analysis applied to the collected data from the TBC students in towns from the state of Veracruz, Mexico, the variable equality for gender was proven. The results indicate that there are significant differences by gender present in the variable Mathtest $(\mathrm{F}=14.282)$ and Mathtasks $(F=4.004)$, with a critical $F$ value of 3.888 and a significance of .05 . The studies done by [8], [27], [29] and also found significant differences by gender in the anxiety variables.

In contrast, the variable Mathcourses $(\mathrm{F}=.881) \mathrm{F}$ found $<$ critical $\mathrm{F}$, therefore there are no significant differences by gender. The former agrees with the work of [31], who also didn't find significant differences by gender in the variables explaining math anxiety.

The three-dimensional model of RMARS scale with the influence of gender over two variables is shown in Figure 3.

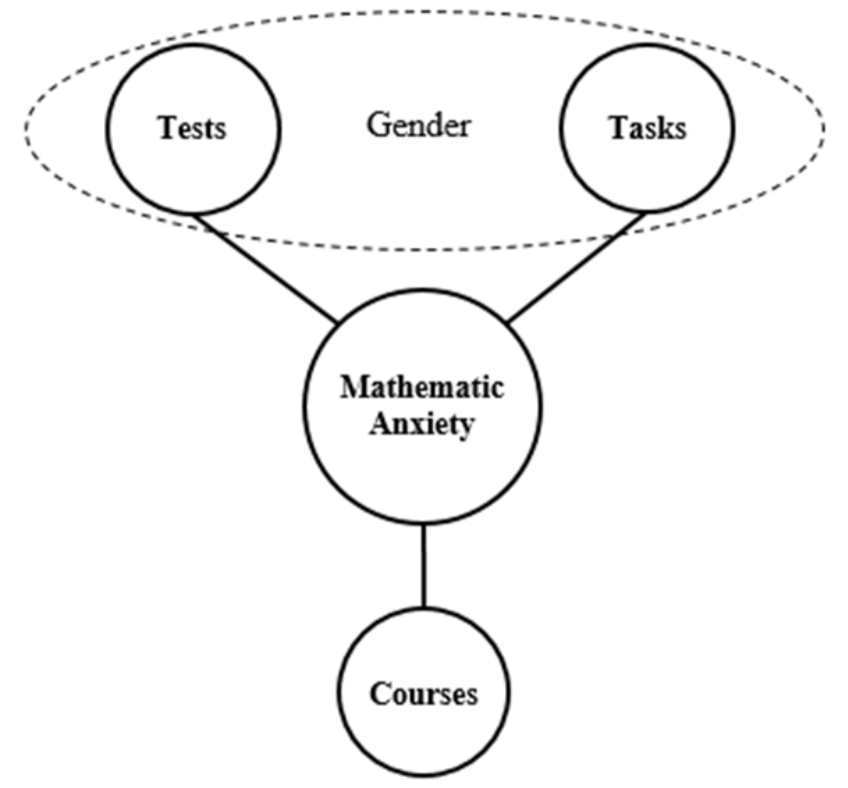

Figure 3. Three-dimensional model of RMARS scale and the influence of gender Source: by author

\subsection{Recommendations and Future Line of Research}

In the study the variables that explain the math anxiety phenomenon were identified in students from $\mathrm{TBC}$ in rural communities in the state of Veracruz, Mexico, which will allow to build strategies to confront this issue. The decline of the anxiety levels will give students the opportunity to approach mathematics with a different perspective.

Additionally, a significant difference in terms of gender was achieved in this research for the anxiety variables. As a result, the action plans will depend of the variable that is chosen to act upon and the differences by gender.

Likewise, for future research it is proposed to inquire if anxiety affects academic performance in subjects related to this area of science. Also, to analyze the relationship between anxiety levels and future academic preferences in these students. 


\section{References}

[1]. Gamboa Araya, R. (2014). Relación entre la dimensión afectiva y el aprendizaje de las matemáticas. Revista electrónica educare, 18(2), 117139. http://dx.doi.org/10.15359/ree.18-2.6

[2]. Price, G. R., Mazzocco, M. M., \& Ansari, D. (2013). Why mental arithmetic counts: brain activation during single digit arithmetic predicts high school math scores. Journal of Neuroscience, 33(1), 156-163. https://doi.org/10.1523/JNEUROSCI.2936-12.2013

[3]. Hodges, C. B., \& Kim, C. (2013). Improving college students' attitudes toward mathematics. TechTrends, 57(4), 59-66. https://doi.org/10.1007/s11528-013-0679-4

[4]. Wang, Z., Lukowski, S. L., Hart, S. A., Lyons, I. M., Thompson, L. A., Kovas, Y., ... \& Petrill, S. A. (2015). Is math anxiety always bad for math learning? The role of math motivation. Psychological science, 26(12), 1863-1876. https://doi.org/10.1177/0956797615602471

[5]. OCDE (2016). Resultados de PISA 2015. Nota país. México. Retrieved from: https://www.oecd.org/pisa/PISA-2015-MexicoESP.pdf [accessed: 22 November 2021].

[6]. Planea (2017). Planea. Resultados nacionales 2017. Retrieved from:

http://planea.sep.gob.mx/content/general/docs/2017/R esultadosNacionalesPlaneaMS2017.PDF [accessed: 27 November 2021].

[7]. Maloney, E. A., \& Beilock, S. L. (2012). Math anxiety: Who has it, why it develops, and how to guard against it. Trends in cognitive sciences, 16(8), 404-406. https://doi.org/10.1016/j.tics.2012.06.008

[8]. Núñez-Peña, M. I., Suárez-Pellicioni, M., \& Bono, R. (2013). Effects of math anxiety on student success in higher education. International Journal of Educational Research, 58, 36-43.

[9]. Bieg, M., Goetz, T., Wolter, I., \& Hall, N. C. (2015). Gender stereotype endorsement differentially predicts girls' and boys' trait-state discrepancy in math anxiety. Frontiers in psychology, 6, 1404. https://doi.org/10.3389/fpsyg.2015.01404

[10]. Jameson, M. M., \& Fusco, B. R. (2014). Math anxiety, math self-concept, and math self-efficacy in adult learners compared to traditional undergraduate students. Adult Education Quarterly, 64(4), 306-322. https://doi.org/10.1177/0741713614541461

[11]. Wood, E. F. (1988). Math anxiety and elementary teachers: What does research tell us?. For the learning of mathematics, 8(1), 8-13.

[12]. Atkinson, R. T. (1988). An exploration of the factors relating to the system of mathematics anxiety (Doctoral dissertation, Oklahoma State University).

[13]. Sister Mary Fides Gough, O. P. (1954). Why failures in mathematics? Mathemaphobia: Causes and treatments. The Clearing House: A Journal of Educational Strategies, Issues and Ideas, 28(5), 290294.
[14]. Dreger, R. M., \& Aiken Jr, L. R. (1957). The identification of number anxiety in a college population. Journal of Educational psychology, 48(6), 344. $\quad$ http://dx.doi.org/10.1037/h0045894

[15]. Richardson, F. C., \& Suinn, R. M. (1972). The Mathematics Anxiety Rating Scale: Psychometric Data. Journal of Counseling Psychology, 19(6), 551554. $\quad$ http://dx.doi.org/10.1037/h0033456

[16]. Dutton, W. H., \& Blum, M. P. (1968). The measurement of attitudes toward arithmetic with a Likert-type test. The Elementary School Journal, 68(5), 259-264. https://doi.org/10.1086/460443

[17]. Fennema, E., \& Sherman, J. A. (1976). FennemaSherman mathematics attitudes scales: Instruments designed to measure attitudes toward the learning of mathematics by females and males. Journal for research in Mathematics Education, 7(5), 324-326. https://doi.org/10.2307/748467

[18]. Sandman, R. S. (1980). The mathematics attitude inventory: Instrument and user's manual. Journal for research in Mathematics Education, 11(2), 148-149. https://doi.org/10.2307/748906

[19]. Plake, B. S., \& Parker, C. S. (1982). The development and validation of a revised version of the Mathematics Anxiety Rating Scale. Educational and psychological measurement, 42(2), 551-557. https://doi.org/10.1177/001316448204200218

[20]. Suinn, R. M., \& Winston, E. H. (2003). The mathematics anxiety rating scale, a brief version: psychometric data. Psychological reports, 92(1), 167173. $\quad$ https://doi.org/10.2466/pr0.2003.92.1.167

[21]. Hopko, D. R. (2003). Confirmatory factor analysis of the math anxiety rating scale-revised. Educational and psychological measurement, 63(2), 336-351. https://doi.org/10.1177/0013164402251041

[22]. Alexander, L., \& Martray, C. (1989). The development of an abbreviated version of the Mathematics Anxiety Rating Scale. Measurement and Evaluation in counseling and development, 22(3), 143-150.

[23]. Cantero, J. M. M., \& Vázquez, D. M. (2007). Elaboración y estructura factorial de un cuestionario para medir la" ansiedad hacia las Matemáticas" en alumnos de Educación Secundaria Obligatoria. Revista galego-portuguesa de psicoloxía e educación: revista de estudios e investigación en psicología y educación, (14), 221-234.

[24]. García-Santillán, A., Escalera-Chávez, M. E., Moreno-García, E., \& del Carmen Santana-Villegas, J. (2016). Factors that explains student anxiety toward mathematics. Eurasia Journal of Mathematics, Science and Technology Education, 12(2), 361-372. https://doi.org/10.12973/eurasia.2016.1216a

[25]. Moreno-García, E., \& Salazar, N. L. (2016). Anxiety toward mathematics on "telesecundaria" students. Revista INFAD de Psicología. International Journal of Developmental and Educational Psychology., 1(2), 453-464. https://doi.org/10.17060/ijodaep.2016.n2.v1.546 
[26]. González-Pienda, J. A., Fernández-Cueli, M., García, T., Suárez, N., Fernández, E., Tuero-Herrero, E., \& da Silva, E. H. (2012). Diferencias de género en actitudes hacia las matemáticas en la Enseñanza obligatoria. Revista Iberoamericana de Psicología y Salud, 3(1), 55-73.

[27]. Pérez-Tyteca, P., Martínez, E. C., Romero, L. R., \& Martínez, E. C. (2011). Ansiedad matemática, género y ramas de conocimiento en alumnos universitarios. Enseñanza de las ciencias: revista de investigación y experiencias didácticas, 237-250.

[28]. Hill, F., Mammarella, I. C., Devine, A., Caviola, S., Passolunghi, M. C., \& Szücs, D. (2016). Maths anxiety in primary and secondary school students: Gender differences, developmental changes and anxiety specificity. Learning and individual differences, 48, 45-53. http://dx.doi.org/10.1016/j.lindif.2016.02.006

[29]. Hembree, R. (1990). The nature, effects, and relief of mathematics anxiety. Journal for research in mathematics education, 21(1), 33-46. https://doi.org/10.2307/749455
[30]. Baloglu, M., \& Kocak, R. (2006). A multivariate investigation of the differences in mathematics anxiety. Personality and Individual Differences, 40(7), 1325-1335. https://doi.org/10.1016/j.paid.2005.10.009

[31]. Tejedor, B., Santos, M. A., García-Orza, J., Carratalà, P., \& Navas, M. (2009). Variables explicativas de la ansiedad frente a las matemáticas: un estudio de una muestra de $6^{\circ}$ de primaria. Anuario de psicología, 40(3), 345-355.

[32]. García-Santillán, A. (2017). Measuring Set Latent Variables Through Exploratory Factor Analysis with Principal Components Extraction and Validation with AMOS Software. European Journal of Pure and Applied Mathematics, 10(2), 167-198.

[33]. Hair, J. F. (1999). andersOn, r. e.; tatHaM, r. L.; bLack, W. c. Multivariate data analysis, 5.

[34]. Oviedo, H. C., \& Campo-Arias, A. (2005). Aproximación al uso del coeficiente alfa de Cronbach. Revista colombiana de psiquiatría, 34(4), 572-580. 